ISSN: 1980-055X

Recebido em: 26/04/2010

Aceito para publicação em: 20/07/2010

\title{
A PARTICIPAÇÃO DOS SISTEMAS ATMOSFÉRICOS ATUANTES NA BACIA DO RIO PARANÁ NO PERÍODO 1980 A 2003
}

\author{
Victor da Assunção Borsato ${ }^{12}$ \\ Edvard Elias de Souza Filho ${ }^{13}$
}

\begin{abstract}
RESUMO
A climatologia geográfica pode contribuir com as ciências que buscam, no meio físico, seus objetos de estudo, principalmente hoje, diante do quadro de mudanças climáticas globais. Para a caracterização do clima da vertente ocidental do alto rio Paraná estudou-se a dinâmica climática no período de 1980 a 2003. Através da análise rítmica e da dinâmica das massas de ar, determinaram-se os tempos médios das participações dos sistemas atmosféricos atuantes e as porcentagens das chuvas convectivas e frontais. Os resultados permitiram estabelecer uma faixa limite para os dois tipos de chuva. Verificouse que nas localidades de menores latitudes, nos meses mais quentes, além de predominar a atuação dos sistemas de baixa pressão, predominam as chuvas convectivas. À medida que aumenta a latitude, aumenta também a participação dos sistemas de alta pressão e das chuvas frontais. Verificou-se também que os sistemas de baixa pressão estão ampliando o tempo de atuação, assim como as chuvas convectivas.
\end{abstract}

Palavras chave: sistemas atmosféricos, análise rítmica, pluviosidade, bacia do Paraná.

\begin{abstract}
The geographical climatology can contribute with the sciences that search for their study objects in the physical environment, especially nowadays and with a situation of global climatic changes. In order to characterize the climate on the Western slope of Upper Paraná River, the climatic dynamics from 1980 to 2003 were studied. By using rhythmic analysis and the air masses dynamics, it was determined the average participation time of the actuating atmospheric system and the percentage shared by convective and frontal types of rain. The results turned it possible to establish a strip limit for the two rain types. It was noted that, in places with smaller latitudes, in the hottest months, besides the prevailing action of low atmospheric pressure systems, convective rains are also

\footnotetext{
12 Professor doutor - Departamento de Geografia FECILCAM e FAFIJAN victorborsato@yahoo.com.br

13 Professor doutor - Departamento de Geografia UEM - edvardmarilia@wnet.com.br
} 
predominant. As latitude increases, the participation of high pressure systems and frontal rains also increase. It were also noted that the low pressure systems are increasing their participation share, along with convective rains.

Key Words: Atmospheric Systems; Rhythmic Analysis; Pluviosity, Paraná Basin.

\section{INTRODUÇÃO}

$\mathrm{Na}$ zona tropical, as chuvas assumem o papel de destaque na compreensão do clima. Em escala regional, a precipitação pode ser considerada como o principal elemento de análise na organização e no planejamento territorial e ambiental, em função do elevado grau de interferência, impacto e repercussão no tempo e no espaço. (SANT'ANNA NETO: 1998).

As bacias de drenagem possuem forte relação com as condições climáticas, visto que seu funcionamento depende do aporte de água pluvial. Nas bacias de pequeno porte a variabilidade climática em geral é pequena, mas nas bacias de grande porte as diferenças na sucessão do tempo podem ter papel importante no que diz respeito ao aporte de água e no funcionamento do sistema de drenagem.

No caso da bacia do rio Paraná tal tipo de situação já foi evidenciada por COMUNELLO (2001). O autor verificou que as cheias na planície do rio Paraná, nas proximidades de Porto Rico, podem ser causadas não só pelo próprio rio, mas também pelo rio Ivinheima e pelo rio Baía, em períodos diferentes e como resposta à precipitação ocorrida em locais distintos. Da mesma forma, DESTEFANNI (2005), demonstrou que as cheias do rio Ivaí podem ocorrer em qualquer época do ano, de forma independente do regime de descarga do rio Paraná e isso já ocorria antes deste estar controlado por barragens.

O trabalho de BORSATO (2006) demonstrou que em 1980 a maior parte dos eventos de chuva no Estado do Paraná e na parte sul do Mato Grosso do Sul foram causados por Sistemas Frontais, enquanto que na parte norte da bacia a maior contribuição pluviométricos teve origem convectiva, uma vez que os sistemas frontais e a massa Polar atlântica raramente atuaram ao norte das divisas entre Mato Grosso do Sul e Goiás e de São Paulo e Minas Gerais. Dessa forma, os rios da parte meridional da bacia tiveram aporte de água durante todo o período, enquanto os rios setentrionais foram abastecidos apenas durante o período quente.

O estudo de ZAVATINI (1991) sobre o clima do Estado do Mato Grosso do Sul, considerou que o estado está situado em uma zona de encontro entre as massas de ar tropicais e polares e por isso é cortado por uma faixa divisória situada aproximadamente a - 21030' de latitude na divisa com São Paulo e a 20000' na fronteira com a Paraguai e Bolívia. Essa faixa limite da transição passa também nas proximidades da cidade de Campo Grande.

Ao sul dessa faixa, o clima é controlado por massas de ar tropicais e polares e a norte dela, é controlado por massas de ar tropicais e equatoriais. Contudo, BORSATO (2006) situou tal limite em posição um pouco mais ao norte.

Este trabalho pretende estudar a dinâmica das massas de ar na bacia do rio Paraná no período entre 1980 e 2003, com o intuito de verificar o efeito da latitude sobre a influência das massas de ar, a origem da chuva ao longo do 
transeto Maringá, Campo Grande, Goiânia, alem de reavaliar a posição do limite de atuação da massa Polar atlântica e dos sistemas frontais.

\section{PROCEDIMENTOS METODOLÓGICOS}

A proposta da análise rítmica de MONTEIRO (1971) e o estudo da dinâmica das massas de PÉDELABORDE (1970) para caracterizar o tempo atmosférico através da dinâmica da circulação regional fundamentam o objetivo desse trabalho.

De acordo com MONTEIRO (1971), o ritmo climático só poderá ser compreendido através da representação concomitante dos elementos fundamentais do clima em unidades de tempo cronológico, pelo menos diárias, compatíveis com a representação da circulação atmosférica regional, geradora dos estados atmosféricos que se sucedem e constituem o fundamento do ritmo. Para ZAVATINI (2003), resta, contudo, delimitar mais precisamente até onde, dentro do país, tais características do ritmo climático se manifesta, ou seja, delimitar as áreas através das afinidades rítmicas regionais e sub-regionais. Com base na preocupação deste autor, delimitar as áreas das afinidades rítmicas exigiria tempo e cautela. Este estudo mostra que, além do limite da área de ocorrência das chuvas frontais, pode-se também verificar como a dinâmica dos sistemas atmosféricos determina a estacionalidade da pluviosidade em Goiás.

Uma vez que o estudo de um período do ano ou de um ano padrão pode apresentar resultados diferentes do habitual, este estudo foi realizado a partir da análise dos principais elementos do clima a partir de uma série com período suficiente para caracterizar a dinâmica dos sistemas atmosféricos e da circulação regional.

A escala temporal adotada na investigação foi de 23 anos, compreendendo o período entre 1980 e 2003, com exceção do ano de 1982, cujas cartas sinóticas não foram disponibilizadas pela Marinha do Brasil. Para este intervalo foram utilizados os dados climáticos disponibilizados pelo INMET Instituto Nacional de Meteorologia. A análise espacial adotada foi o da escala regional e realizada por meio do método sintético das massas de ar e nos tipos de tempo (PEDELABORDE:1970).

Com o propósito de realizar a análise rítmica, os dados diários dos principais elementos do tempo das Estações Climatológicas de Maringá, Campo Grande e a de Goiânia, estações de primeira classe, foram organizados em planilhas mensais e analisados. Os registros da estação climatológica de Campo Grande apresentam falhas nos dados até 1992. Uma vez que as lacunas às vezes superavam o período de um mês, foi necessário realizar o descarte dos dados dessa estação no período entre 1980 e 1992. Dessa forma, os dados relativos à cidade de Campo Grande são auxiliares e a ênfase principal foi dada à variação entre Maringá e Goiânia.

Os sistemas atmosféricos considerados no estudo foram aqueles que atuaram no Centro-Sul do Brasil, ou seja: Sistema Frontal (SF), massa Tropical continental (mTc), massa Tropical atlântica (mTa), massa Polar atlântica (mPa), massa Equatorial continental (mEc), e sistema de Cavado (CV), (VIANELLO: 2000; VAREJÃO-SILVA: 2000; FERREIRA: 1989).

Para identificar a atuação dos sistemas atuantes, foram elaboradas tabelas em planilhas anuais subdivididas em unidades mensais com colunas 
para os dias e para os sistemas atmosféricos atuantes na cidade de Maringá, de Campo Grande e de Goiânia.

A partir dos dados organizados em planilha, foi identificado através da análise das cartas sinóticas da Marinha do Brasil, das imagens de satélite no canal infravermelho e nos registros dos elementos do tempo o sistema atmosférico que atuava na região de estudo. Foram atribuídos valores de 12 ou 24, representando as horas do dia. Quando a carta sinótica mostrava a confluência entre dois sistemas atmosféricos, foi atribuído o valor 12 para cada um, levando-se em consideração a carta do dia anterior e a do dia seguinte, e 24 para as localidades onde um único sistema dominava o tempo. Os valores diários de cada mês foram somados e foi calculada a porcentagem da participação mensal para cada sistema. Também foram calculadas as participações, anual e nas estações do ano.

Os dados dos elementos do tempo foram organizados em tabelas mensais. Foram confeccionados gráficos mensais com os dados diários dos elementos do clima (pressão atmosférica da superfície -12 TMG., temperaturas máximas, médias e mínimas, nebulosidade, ou insolação, precipitação acumulada, vento - direção 12 TMG.). Além disso, foram acrescentados os sistemas atmosféricos atuantes. A elaboração dos gráficos foi realizada por meio do o programa computacional "RITMOANALISE" (BORSATO et al., 2004).

As três estações climatológicas escolhidas encontram-se bastante distantes entre si e para aumentar a resolução espacial, foram escolhidos postos pluviométricos localizados no Paraná, no Mato Grosso do Sul e em Goiás, cujos dados foram fornecidos pelo Ministério da Agricultura do Governo Federal. Os postos escolhidos foram todos aqueles que apresentaram dados da pluviosidade diária sem falhas e se encontravam circunscritos na área de estudo. Dentre o conjunto, 9 postos situam-se no Estado do Paraná, 11 no Estado de Mato Grosso do Sul e 12 em Goiás (Figura 01). Os dados foram organizados em tabelas e foram elaborados gráficos em 3D, utilizando as planilhas do Microsoft Excel disponibilizado na seqüência de conformidade com a latitude dos postos.

Os sistemas frontais puderam ser acompanhados por imagens de satélite no canal infravermelho a partir de 1994 e também pelos informativos do CPTEC-INPE, CLIMANÁLISE: 1995, 1996, 1997, 1998, 1999, 2000, 2001, 200 e 2003. De posse dos dados e gráficos, foi realizada a análise rítmica.

Os gráficos da análise rítmica foram organizados anualmente em pranchas no Corell Draw 10 e organizados na seqüência, Goiânia, Campo Grande e Maringá. O objetivo foi verificar a espacialização temporal dos sistemas atmosféricos atuantes, ou seja, auxiliar a interpretação das massas de ar atuantes e caracterizar os tipos de tempo.

A análise da pluviosidade considerou apenas os aspectos qualitativos, pois a sua gênese foi o objetivo. Para classificá-la como frontal ou convectiva foi utilizada a tabela dos sistemas atuantes. As chuvas registradas nos dias que atuavam os sistemas frontais ou a massa Polar atlântica foram consideradas frontais enquanto aquelas registradas em dias de domínios dos demais sistemas atmosféricos foram consideradas convectivas.

O número de dias de precipitação frontal e de convectiva de cada estação foram somados em cada mês e calculados a porcentagem mensal, para as estações e para o ano. Os valores obtidos foram sintetizados em gráficos e comparados entre si. 


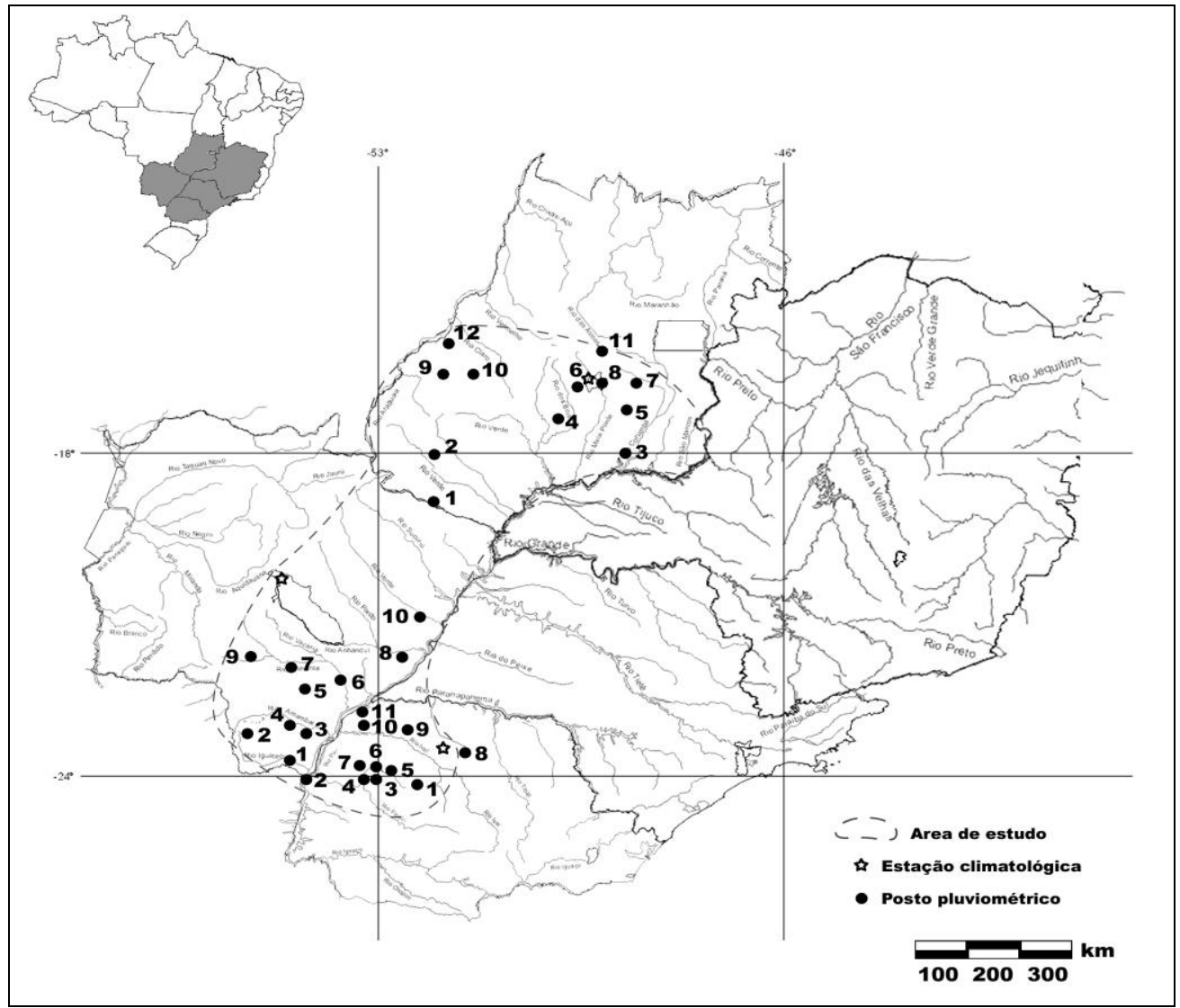

Figura 01. Localização da área de estudos e distribuição dos postos pluviométricos nos estados do Paraná, Mato Grosso do Sul e Goiás. (Postos anexos)

\section{RESULTADOS E DISCUSSÃo}

Os resultados que seguem foram obtidos a partir da análise rítmica executada para a série e principalmente da análise da dinâmica das massas de ar. Tal trabalho resultou na elaboração de 276 tabelas e gráficos com os dados diários de cada mês. Na impraticabilidade de apresentar tais tabelas e gráficos associados na íntegra, optou-se em discutir os resultados relevantes e apresentá-los em gráficos sintéticos.

\section{A permanência das massas de ar}

No período estudado, a cidade de Maringá esteve sob domínio de todos os sistemas que atuaram no Centro Sul do Brasil. No período estudado, a ordem de atuação dos sistemas foi a seguinte: $\mathrm{mPa}(38,6 \%)$, SF $(23,1 \%)$, mTc $(17,8 \%)$, mTa $(15,1 \%)$, mEc $(3,6 \%)$ e CV $(1,8 \%)$. A permanência anual pode ser observada na Figura 02.

Os sistemas mPa, mEc e CV mostraram tendência a um aumento da atuação ao longo do período, enquanto os sistemas SF, mTa, e mTc mostraram tendência à diminuição em sua permanência. 


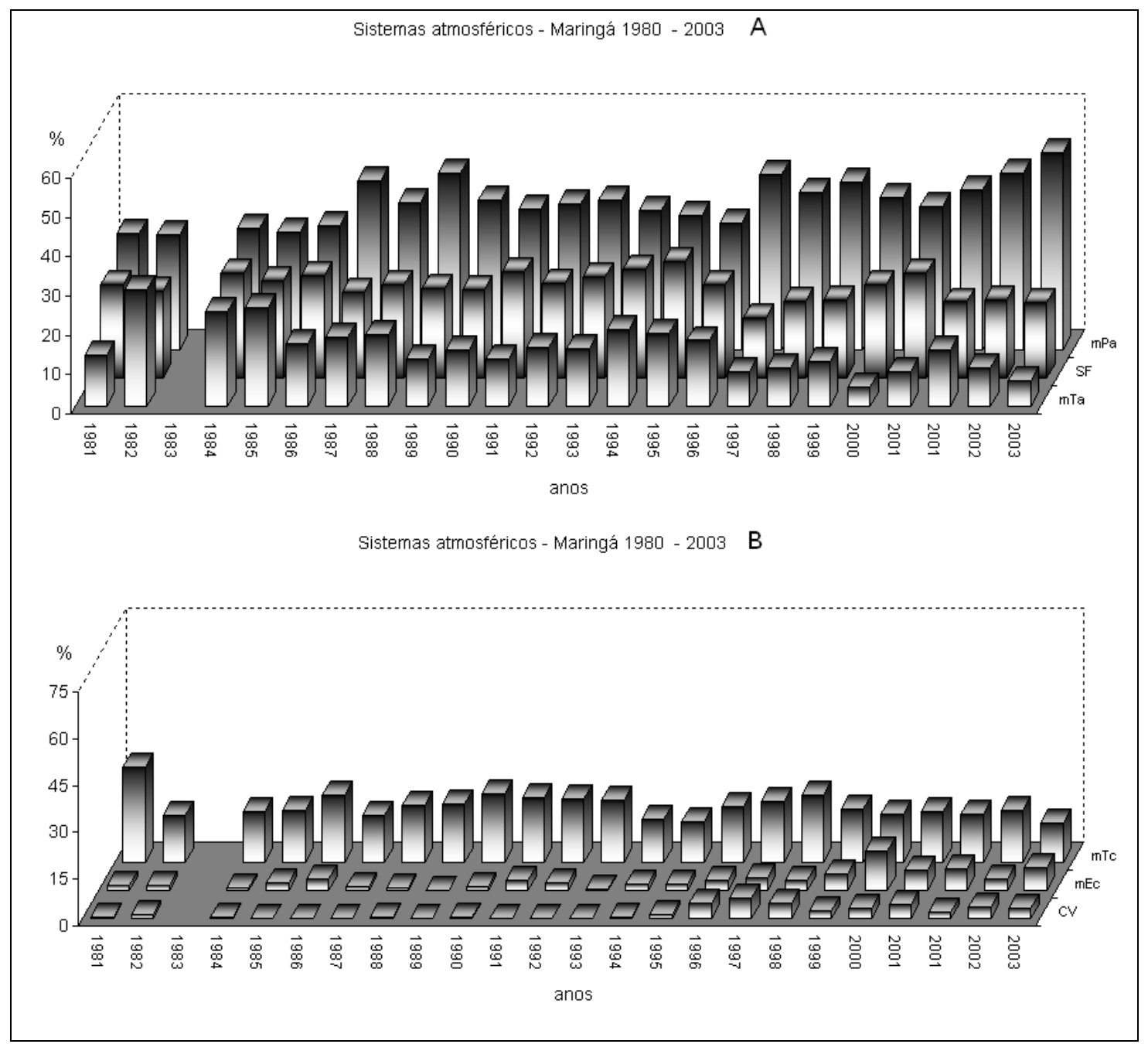

Figura 02. Distribuição, em porcentagem do tempo de atuação dos sistemas atmosféricos em Maringá, na série 1980 - 2003, divididos em A e B $(A=m P a$, $\mathrm{mTa}$ e SF e $\mathrm{B}=\mathrm{mTc}$, $\mathrm{mEc}, \mathrm{CV}$ ) para melhorar a leitura.

A cidade de Campo Grande é a que se encontra mais afastada do litoral entre as três estudadas. Por isso, os dois sistemas de baixa pressão com origem no interior do continente somaram a maior porcentagem de participação. A ordem de atuação foi: $\operatorname{mTc}(41,3 \%), \operatorname{mPa}(25,3 \%), \operatorname{mEc}(18,3 \%)$, SF $(8,9 \%)$, $\mathrm{mTa}(4 \%)$ e CV $(2,2 \%)$, conforme a Figura 03.

Os sistemas $\mathrm{mPa}, \mathrm{mEc}$ e $\mathrm{CV}$ mostraram tendência a aumento de sua atuação ao longo do período, enquanto os sistemas mTa e mTc apresentaram tendência à diminuição. O sistema frontal diminuiu seu tempo de permanência na parte inicial do período, mas voltou a aumentar sua atuação nos quatro últimos anos. A mPa somente atua nos meses mais frios, assim, sua permanência é prolongada nesse intervalo. 


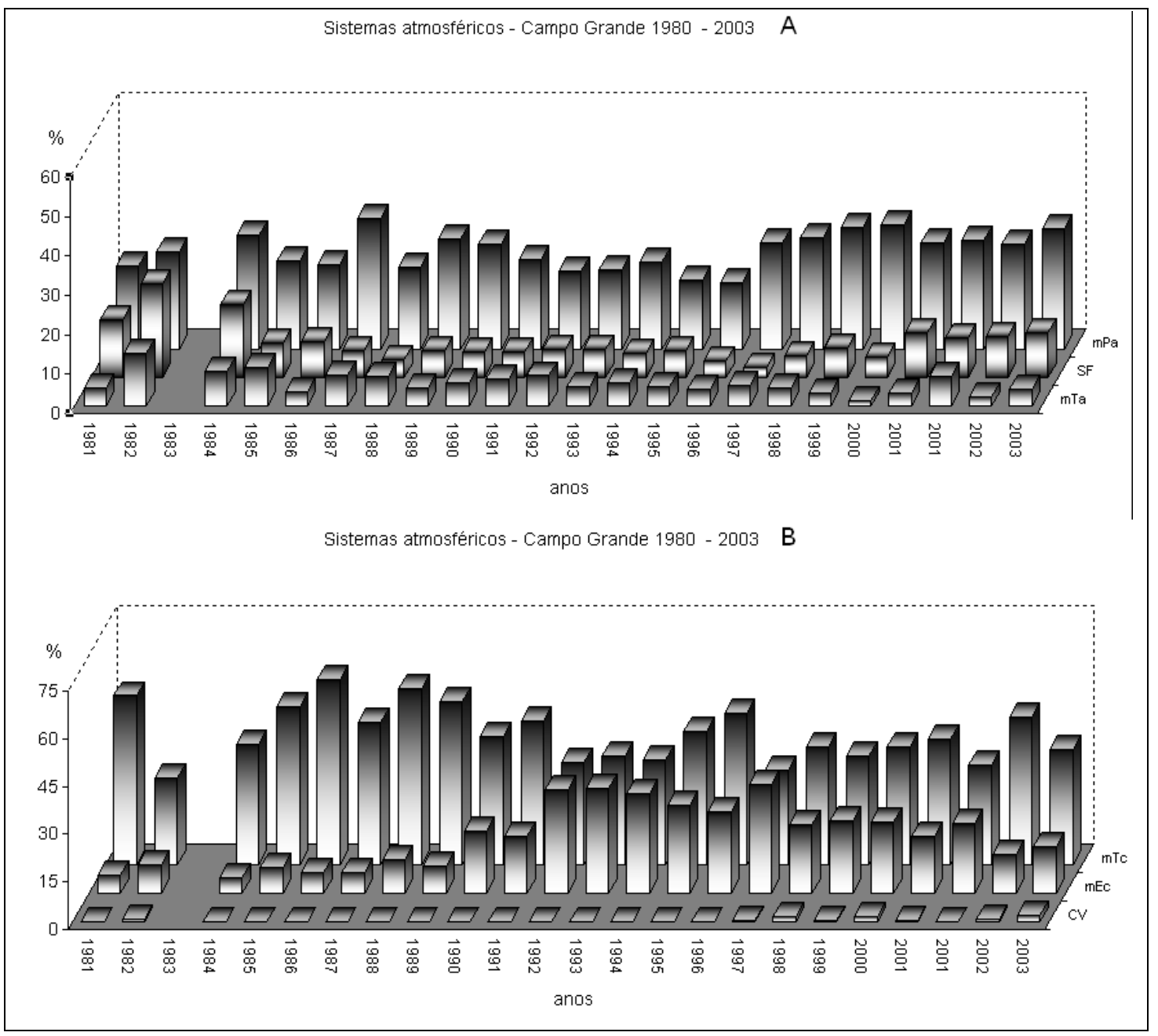

Figura 03. Distribuição, em porcentagem, do tempo de atuação dos sistemas atmosféricos em Campo Grande-MS na série 1993 - 2003, divididos em A e B $(A=\mathrm{mPa}$, SF r mTa e $B=m T c, m E c, C V)$ para melhorar a leitura.

A Estação Climatológica de Goiânia é a de menor latitude e se encontra na porção central do Brasil. Por isso, os sistemas de baixa predominam. A ordem de permanência das massas de ar ao longo do período foi: $\mathrm{mEc}(34,5 \%)$, $\mathrm{mTa}(25,8 \%), \mathrm{mTc}(20,9 \%), \mathrm{mPa}(12,3 \%)$, SF $(6,3 \%)$ e CV $(0,2 \%)$, de acordo com a Figura 04.

A mEc e a mPa mostraram tendência de aumento de atuação no período, enquanto a mTa é a única que mostrou tendência de diminuição. As demais massas não apresentaram uma tendência clara. 


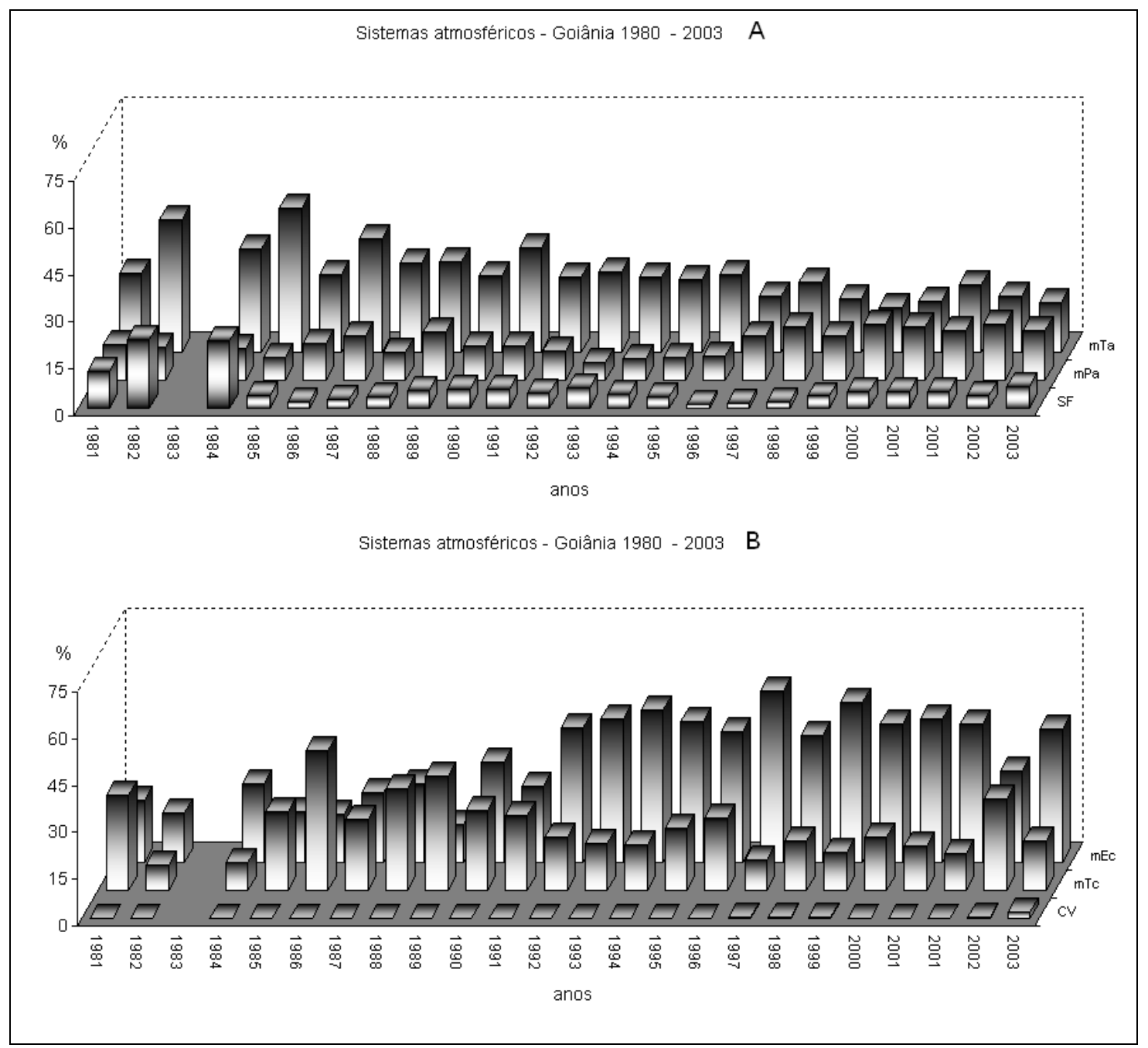

Figura 04. Distribuição, em porcentagem, do tempo de atuação dos sistemas atmosféricos em Goiânia, na série 1980 - 2003 divididos em A e B $(A=m T a$, $\mathrm{mPa}$ e SF e $\mathrm{B}=\mathrm{mEc}, \mathrm{mTc}, \mathrm{CV}$ ) para melhorar a leitura.

A mPa é a massa de ar dominante em Maringá, mas sua atuação diminui para o norte (Figura 05), o que pode ser explicado pelo seu deslocamento em direção ao oceano Atlântico e pela assimilação das características dos locais por onde ela avança. O aumento de sua atuação ao longo do período nas três cidades demonstra que sua penetração em latitudes mais baixas estava sendo mais freqüente.

Os sistemas frontais também diminuíram sua atuação de sul para norte (Figura 06), o que é explicado pelo seu sentido de avanço, de SW para NE. Em Maringá sua atuação tendeu a diminuir, mas em Campo Grande e em Goiânia sua atuação voltou a aumentar no final do período.

Uma vez que os SF estão associados ao avanço da $\mathrm{mPa}$, seria esperado que a variação da permanência do sistema fosse similar à da massa de ar. Contudo, a mPa aumentou sua atuação nas três cidades e o mesmo não ocorreu com o SF. Tal situação pode indicar que ao longo do período tenha ocorrido um 
aumento da velocidade de deslocamento das massas, fazendo com que o SF perdurasse por pouco tempo.

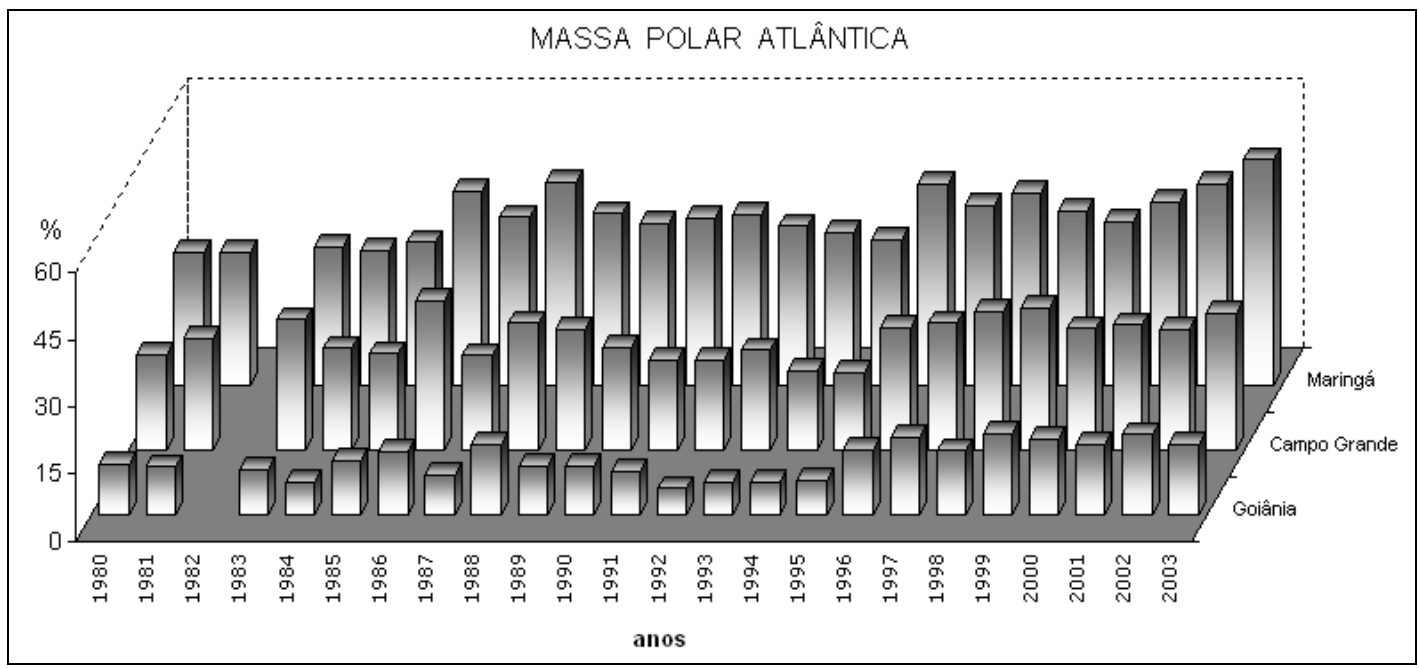

Figura 05. Distribuição em porcentagem da mPa em Maringá, Campo Grande e Goiânia.

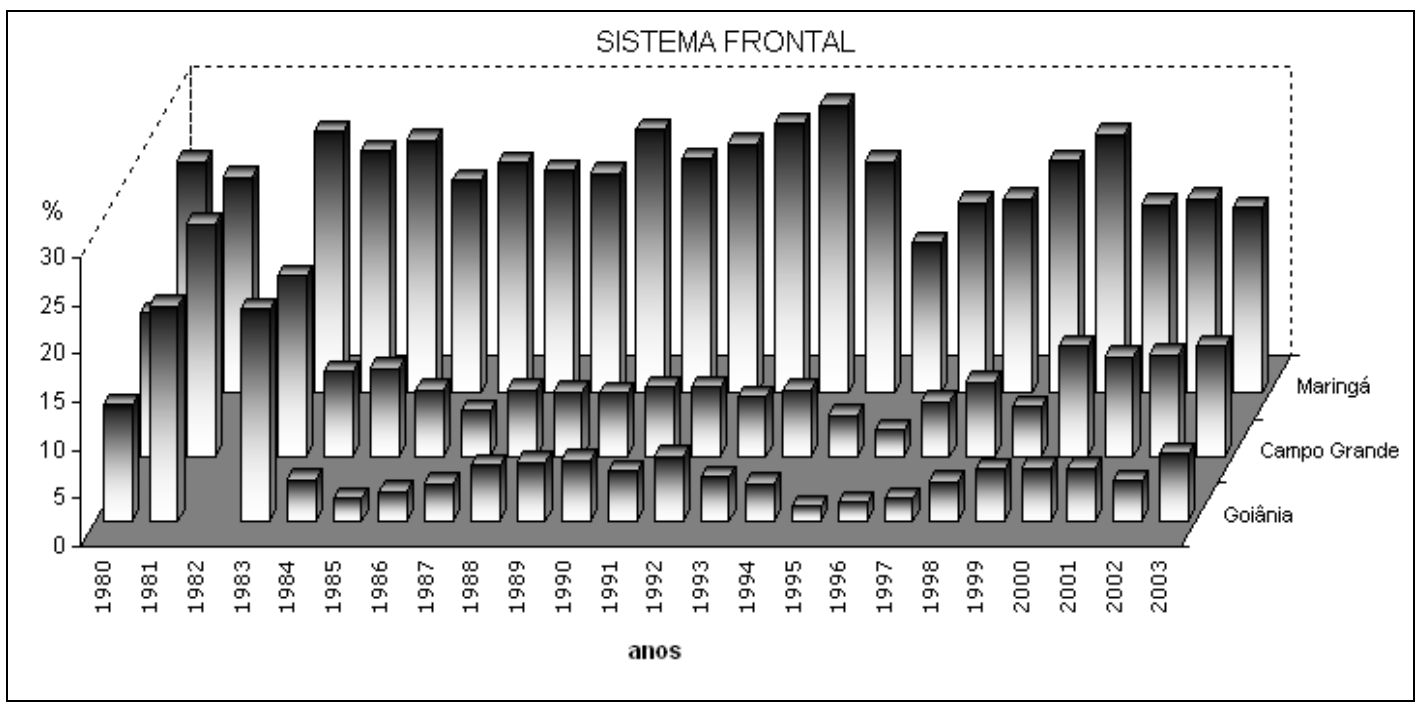

Figura 06. Distribuição, em porcentagem, do SF em Maringá, Campo Grande e Goiânia.

A mEc é um importante sistema, cuja participação na circulação atmosférica da área de estudo é fundamental para a pluviosidade. Ela é uma massa de ar com origem no interior da Amazônia Ocidental, que se expande e avança pelo Centro-Sul do Brasil nos períodos mais quentes. Uma vez que carrega bastante umidade, causa instabilidade do tempo nas áreas atingidas por seu avanço.

A proximidade maior de Goiânia com a região de origem explica porque das três estações climatológicas estudadas a de Goiânia foi dominada por esse sistema e porque sua influência diminui para o sul (Figura 07). O aumento de sua atuação ao longo do período demonstra que o avanço da massa para o sul 
estava sendo mais freqüente e isso é uma indicação de um possível aumento da ocorrência de chuvas convectivas.

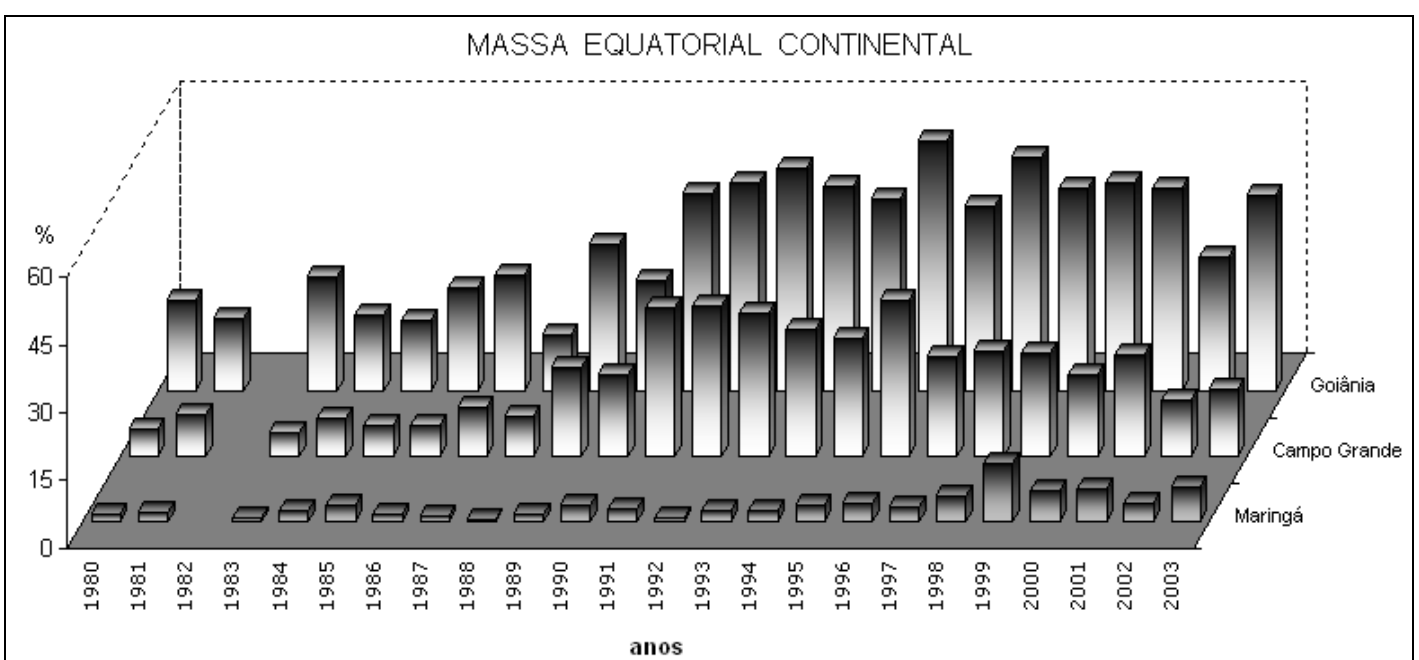

Figura 07. Distribuição, em porcentagem, da mEc em Maringá Campo Grande e Goiânia.

A mTa é um sistema de alta pressão com vórtice no Atlântico Sul, que se intensifica no inverno e avança para o interior do Brasil. Sua atuação é mais pronunciada em Goiânia porque Maringá é fortemente influenciada pela $\mathrm{mPa}$ e Campo Grande está muito distante do litoral.

Ao longo do período analisado, a mTa mostrou declínio em seu tempo de permanência em todas as cidades enquanto o outro sistema de alta pressão $(\mathrm{mPa})$ apresentou maior tempo de atuação. Isso pode indicar que no período entre 1980 e 2003 as massas polares restringiram a atuação das massas oceânicas.

Nos meses de inverno, os sistemas atmosféricos acentuam a dinâmica estabelecida no outono, ou seja, o predomínio de sistemas de alta intercalados com períodos menores de baixa, razão pela qual a nebulosidade é baixa no Brasil Central. Os sistemas frontais que avançam a partir do Sul do Brasil causam chuvas frontais e, às vezes, chegam ao Sul do Estado de Goiás, mas raramente provocam precipitação.

A atuação dos sistemas atmosféricos em Maringá e em Goiânia encontrase na Figura 08. Em Maringá a mPa atuou em 46,7\% do tempo e em Goiânia atuou $20 \%$, mas o SF diminuiu sua permanência em Maringá.

\section{A gênese das chuvas}

Em Maringá as chuvas ocorrem ao longo do ano e raramente um mês seco é registrado. Os meses com maior pluviosidade no período foram dezembro e janeiro e os de menor precipitação foram os de julho e agosto (Figura 09). 


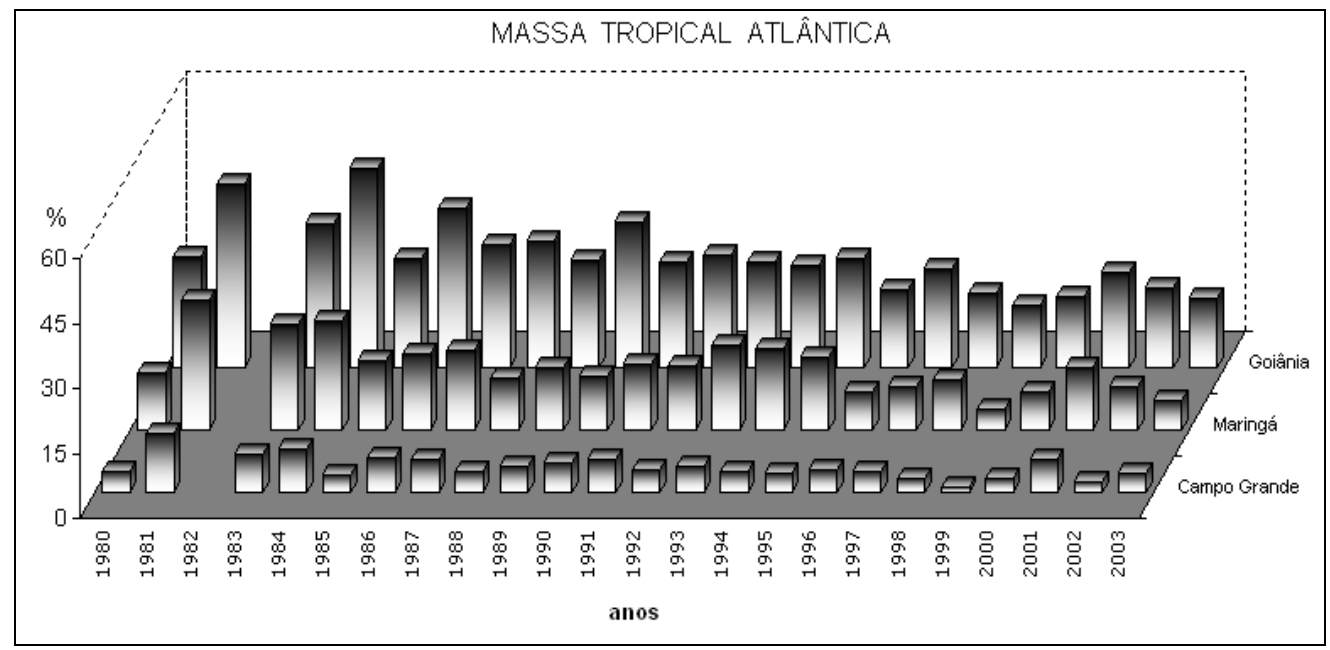

Figura 08. Distribuição, em porcentagem, da mTa em Maringá, Campo Grande e Goiânia.

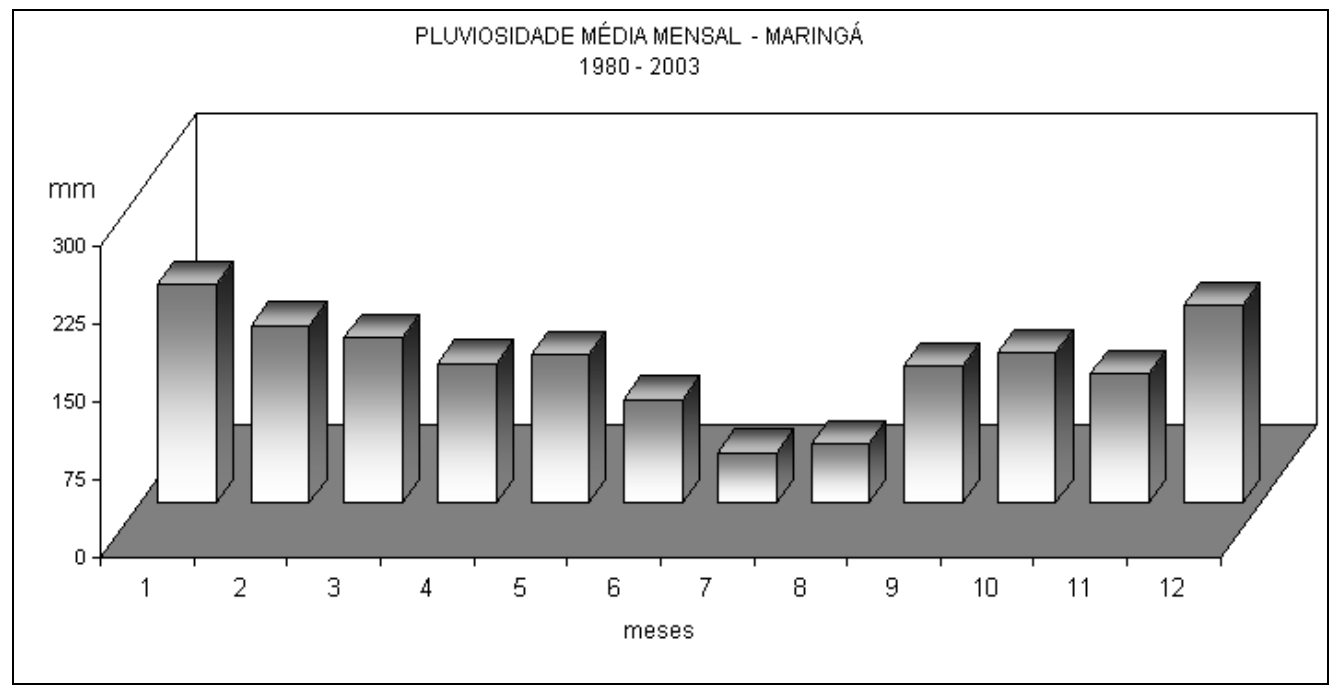

Figura 09 - Pluviosidade média mensal em Maringá entre 1980 e 2003.

As chuvas frontais foram responsáveis por $68,1 \%$ da precipitação no período e foram amplamente dominantes entre abril e outubro. Contudo mesmo nos meses de novembro a março a maior parte da precipitação é causada pelas ZF (Figura 10).

Ao longo do período compreendido entre 1980 e 2003 as chuvas frontais foram dominantes em todos os anos, com exceção de 1984 e 1996 (Figura 11). Apesar disso, este tipo de chuva apresentou tendência à diminuição ao logo do período, acompanhando a diminuição da permanência das ZF. Por outro lado, o aumento da participação das chuvas convectivas acompanha o aumento da participação dos sistemas de baixa pressão (mEc e CV). 


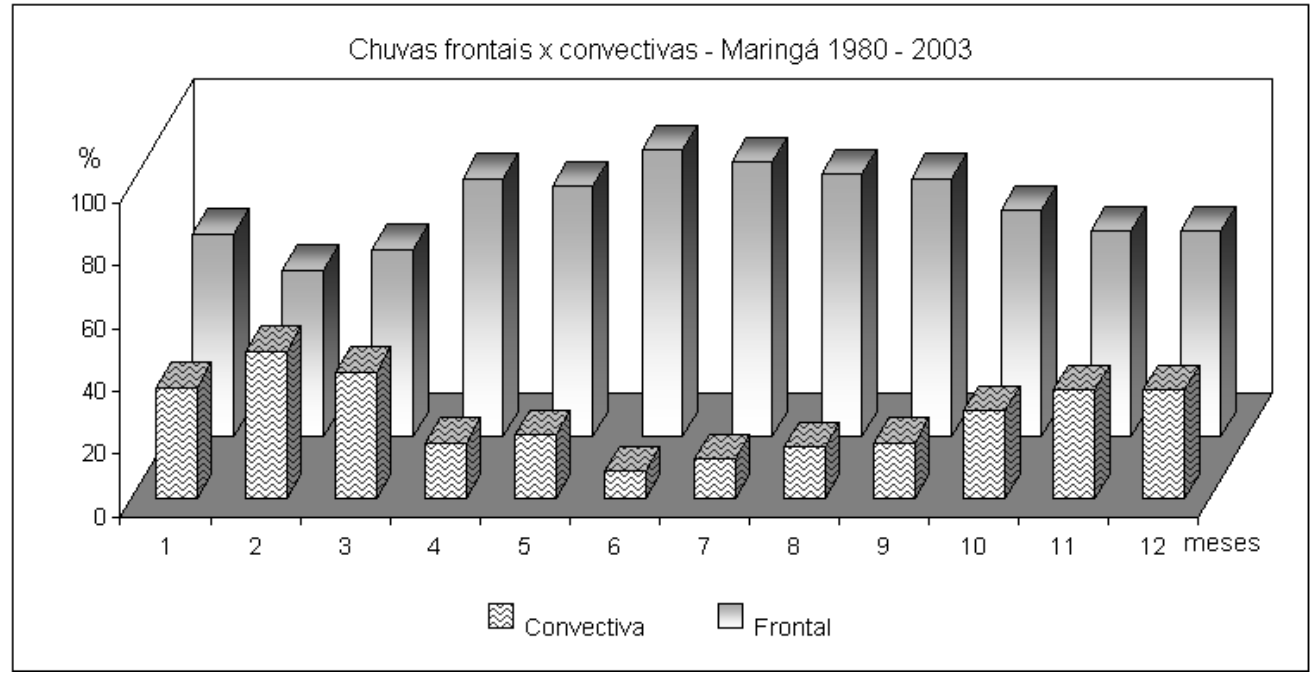

Figura 10. Porcentagem média mensal de chuvas convectivas e frontais em Maringá no período entre 1980 e 2003.

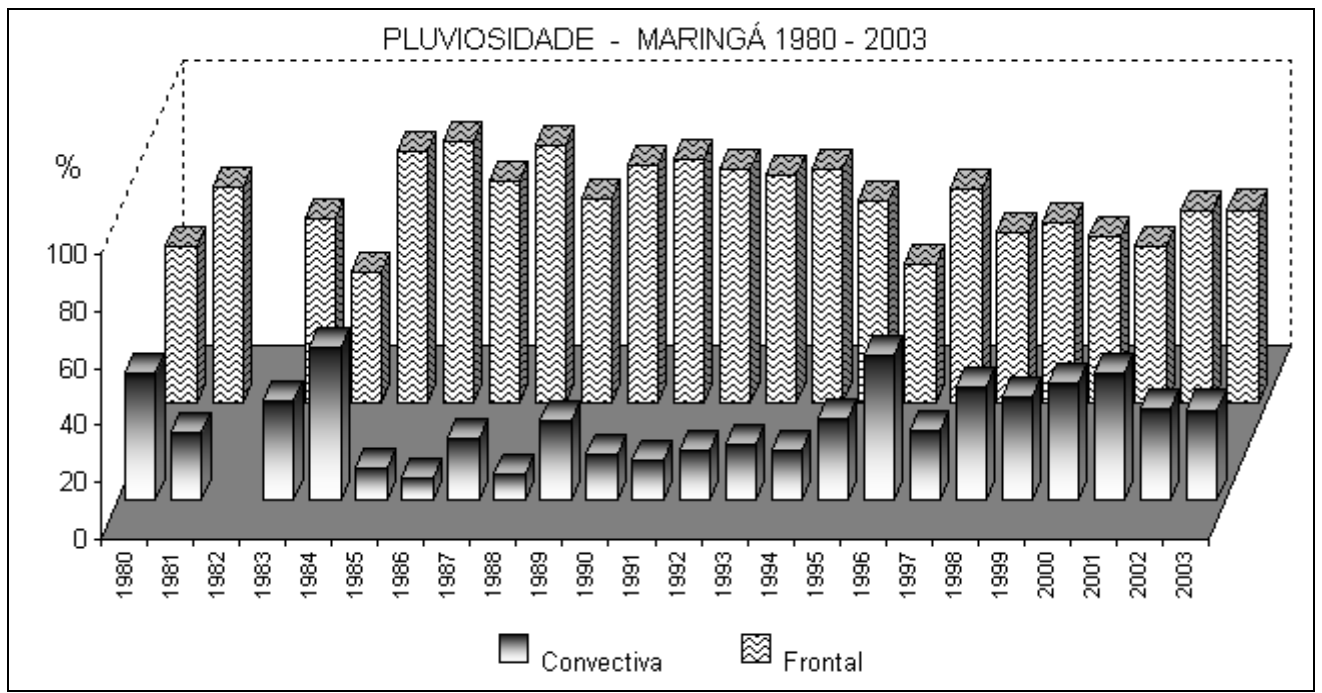

Figura 11. Porcentagem anual de chuvas convectivas e frontais em Maringá no período entre 1980 e 2003.

Em Goiânia as chuvas concentram nos meses mais quentes e há amplo domínio das chuvas convectivas, que totalizaram $88,1 \%$ dos episódios pluviométricos. Isso ocorre porque a região é dominada pelos sistemas de baixa pressão (mEc, mTc) e a participação dos Sistemas Frontais é baixa. Ou seja, encontra-se na zona climática dominado pelas massas de ar equatoriais e tropicais, conforme Zavatini (1991).

Tal situação permite que a distribuição anual das chuvas seja bem definida na parte central do Brasil, com definição clara de verão úmido e inverno seco (Figura 12) 


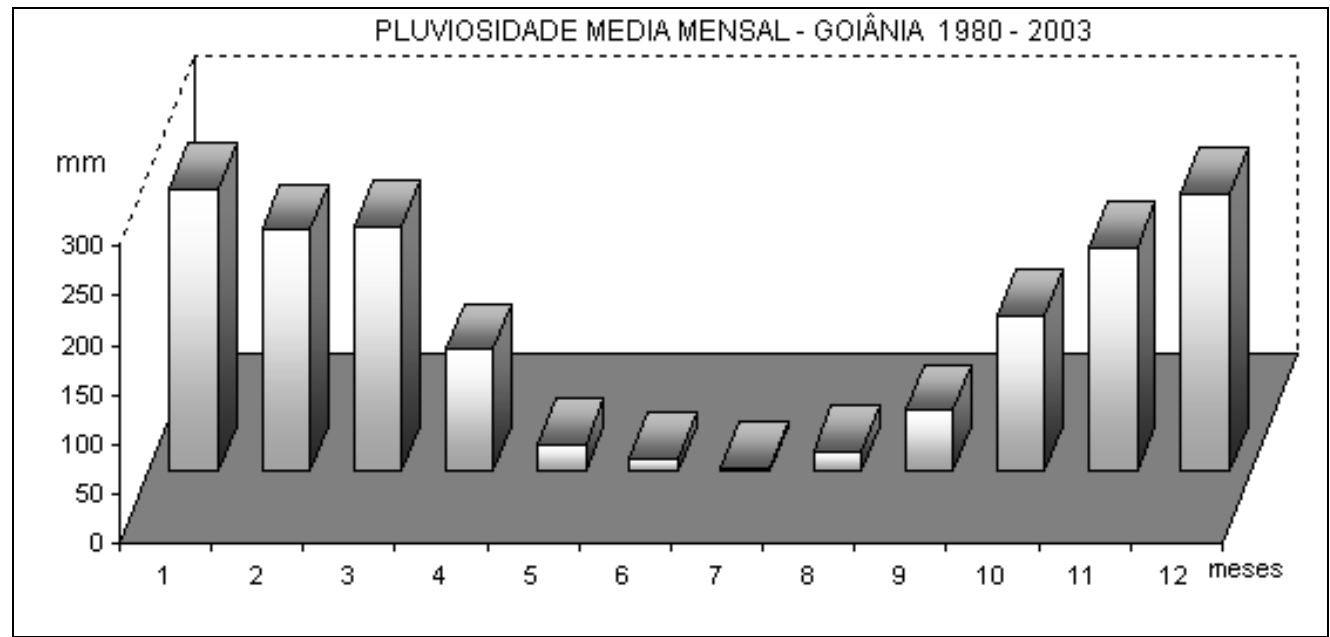

Figura 12. Precipitação média mensal em Goiânia no período de 1980 a 2003.

Dessa forma, as chuvas convectivas foram responsáveis pela maior parte dos acumulados pluviométricos em quase todos os meses. Apenas no mês de julho as chuvas frontais foram responsáveis pela maior parte da precipitação (Figura 13).

As chuvas frontais não mostram uma tendência clara de aumento ou de diminuição ao longo do período estudado (Figura 14), assim como a permanência dos Sistemas Frontais. A comparação entre a variação anual do tempo de permanência das ZF e a porcentagem anual das chuvas frontais demonstra que há forte semelhança entre o comportamento temporal de ambas as variáveis. Contudo, nos anos de 1989, 1990, 1999 e 2003, a porcentagem de chuvas frontais foi proporcionalmente menor que a permanência dos SF.

Esta situação pode ser explicada porque a mPa apenas bordeja a região de Goiânia e em geral causa diminuição da nebulosidade e da umidade, fazendo com que os SF gerem pouca precipitação e também porque a região, nessa época do ano tem baixa umidade relativa.

Os dados da série demonstram que no norte da bacia as chuvas são predominantemente convectivas e na região de Maringá a maior parte das chuvas é originada por sistemas frontais. Contudo, caso a diminuição da permanência deste sistema persista, é possível que a pluviosidade nos meses de abril a outubro venha a diminuir e no futuro uma estação seca passa a existir.

\section{As variações ao longo do ano e a gênese das chuvas}

A participação das massas de ar modifica-se ao longo do ano graças á mudança do ângulo de incidência solar. Dessa forma é necessário analisar a atuação das massas nas diferentes estações do ano.

Durante o verão, a participação dos sistemas de alta pressão é bastante reduzida, totalizando uma média de $7,4 \%$ do tempo cronológico em Goiânia, enquanto em Maringá, o valor sobe para 20,3\% do tempo (Figura 15). As condições de baixa pressão predominantes no verão são condições propícias para os desenvolvimentos de sistemas convectivos de micro e meso-escalas, proporcionando chuvas abundantes. 


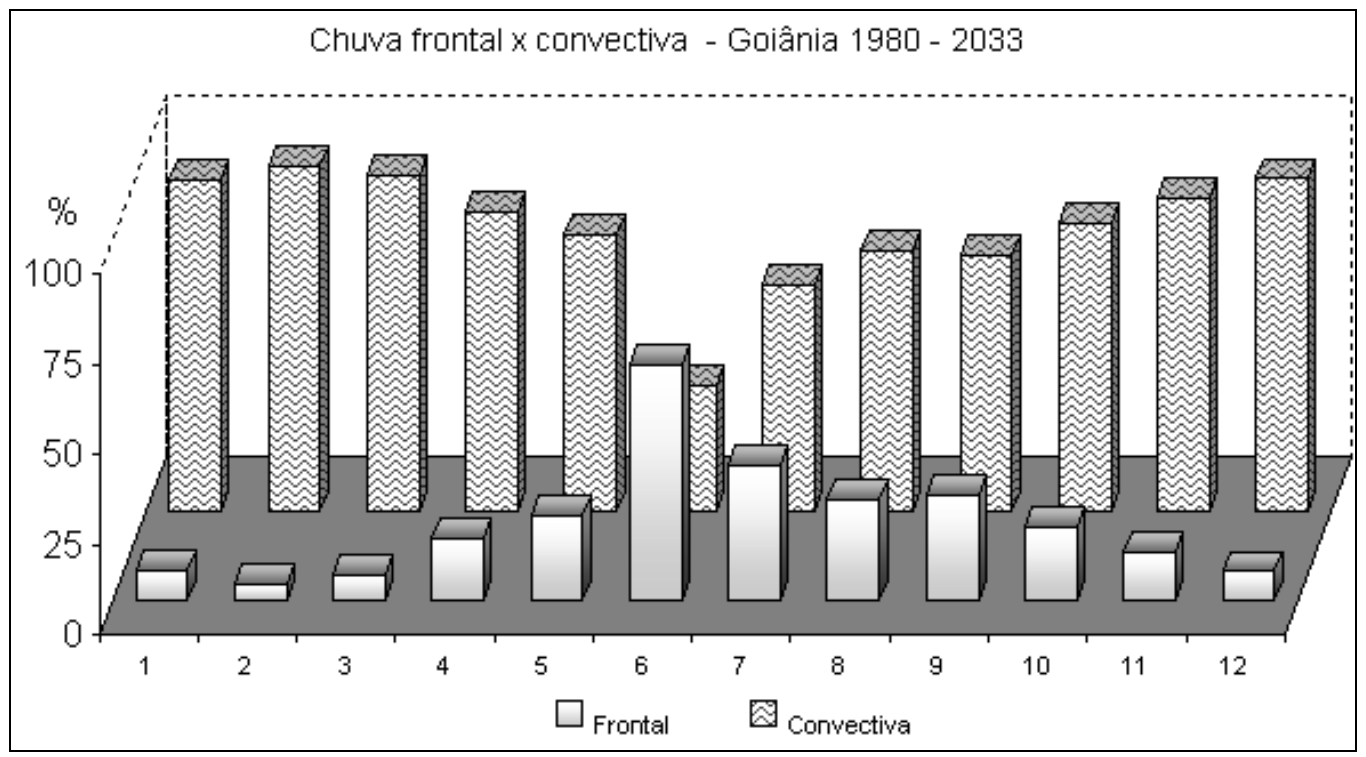

Figura 13. Porcentagem média mensal de chuvas convectivas e frontais em Goiânia no período de 1980 a 2003.

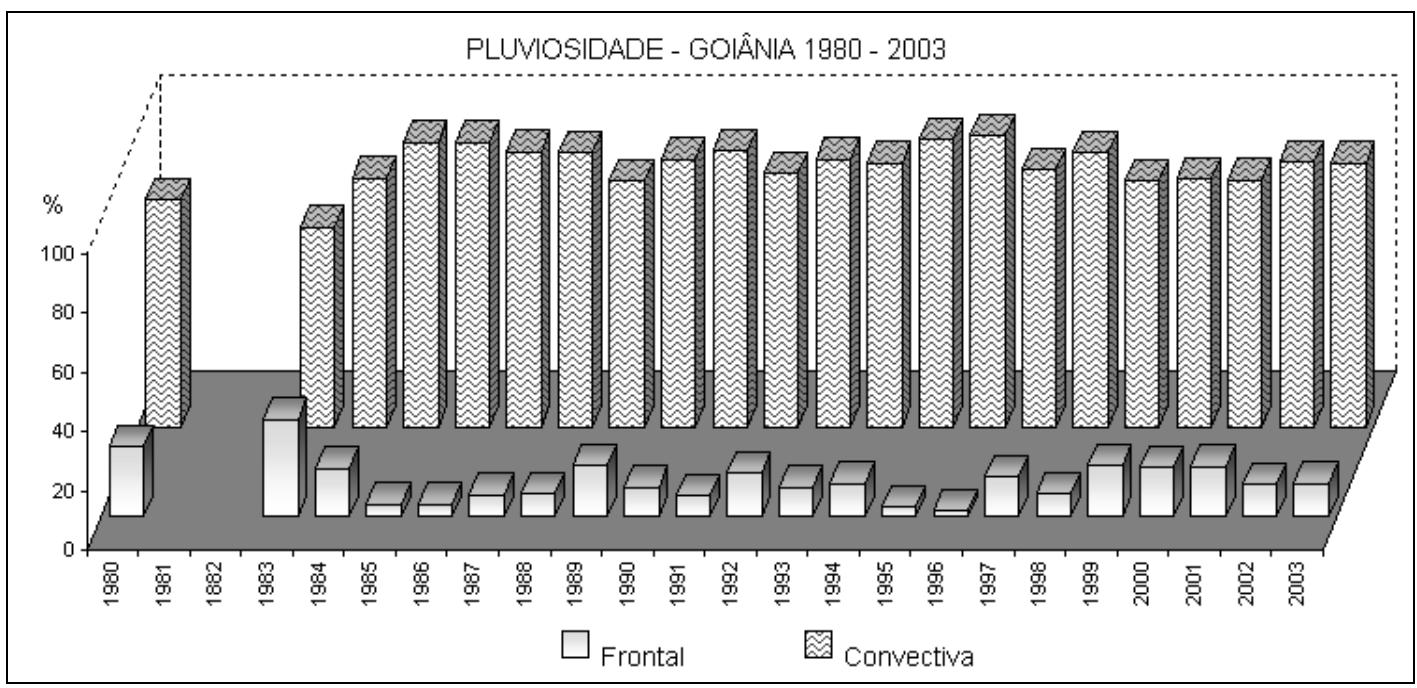

Figura 14. Porcentagem anual de chuvas convectivas e frontais em Goiânia no período de 1980 a 2003. Os anos de 1981 e 1982 não estão incluídos devido a falhas na série histórica.

Dessa forma, as chuvas convectivas que ocorrem em Maringá durante o verão devem estar associadas principalmente à atuação da mEc e mTc, embora o final dos períodos de domínio da mTa possam também ser marcados por precipitação desse tipo. A alta atuação do SF na área explica a razão pela quais as chuvas frontais são dominantes mesmo nesta estação. Em Goiânia, as chuvas convectivas estão associadas principalmente a mEc.

No outono a atuação da mPa aumenta em relação à atuação mostrada no verão, enquanto as massas de baixa pressão diminuem sua atuação (Figura 16). A redução da permanência dos sistemas de baixa pressão diminui a pluviosidade, uma vez que as chuvas convectivas tornam-se menos freqüentes 


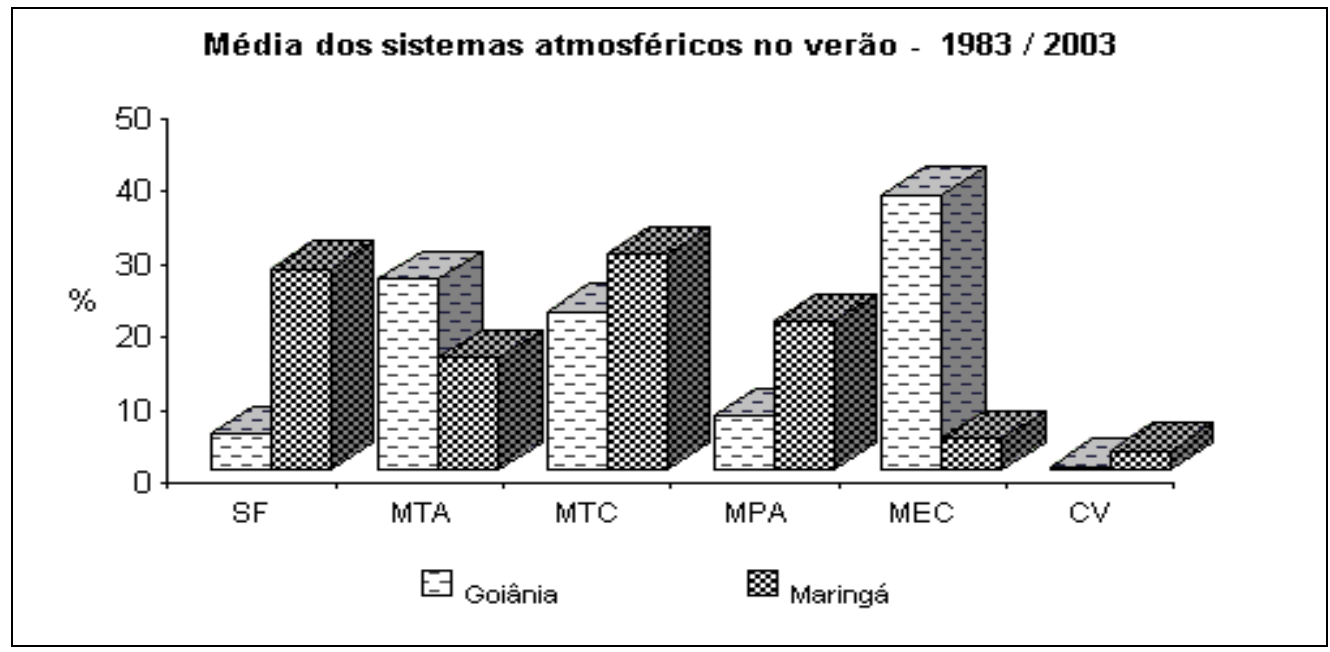

Figura 15. Porcentagem média da permanência dos sistemas atmosféricos em Maringá e em Goiânia na estação de verão, no período entre 1983 e 2003.

Nos meses de inverno, os sistemas atmosféricos acentuam a dinâmica estabelecida no outono, ou seja, o predomínio de sistemas de alta intercalados com períodos menores de baixa, razão pela qual a nebulosidade é baixa no Brasil Central. Os sistemas frontais que avançam a partir do Sul do Brasil causam chuvas frontais e, às vezes, chegam ao Sul do Estado de Goiás, mas raramente provocam precipitação.

A atuação dos sistemas atmosféricos em Maringá e em Goiânia encontrase na Figura 17. Em Maringá a mPa atuou em 46,7\% do tempo e em Goiânia atuou $20 \%$, mas o SF diminuiu sua permanência em Maringá.

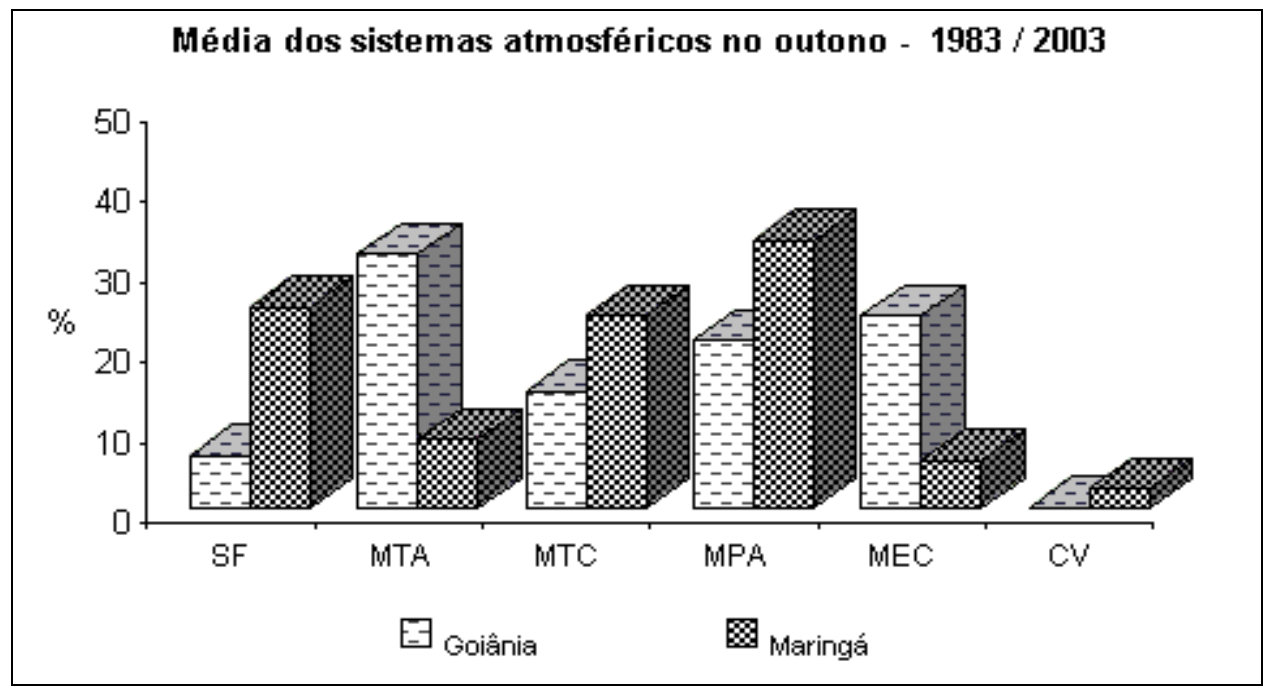

Figura 16. Porcentagem média da permanência dos sistemas atmosféricos em Maringá e em Goiânia na estação de outono, no período entre 1983 e 2003. 


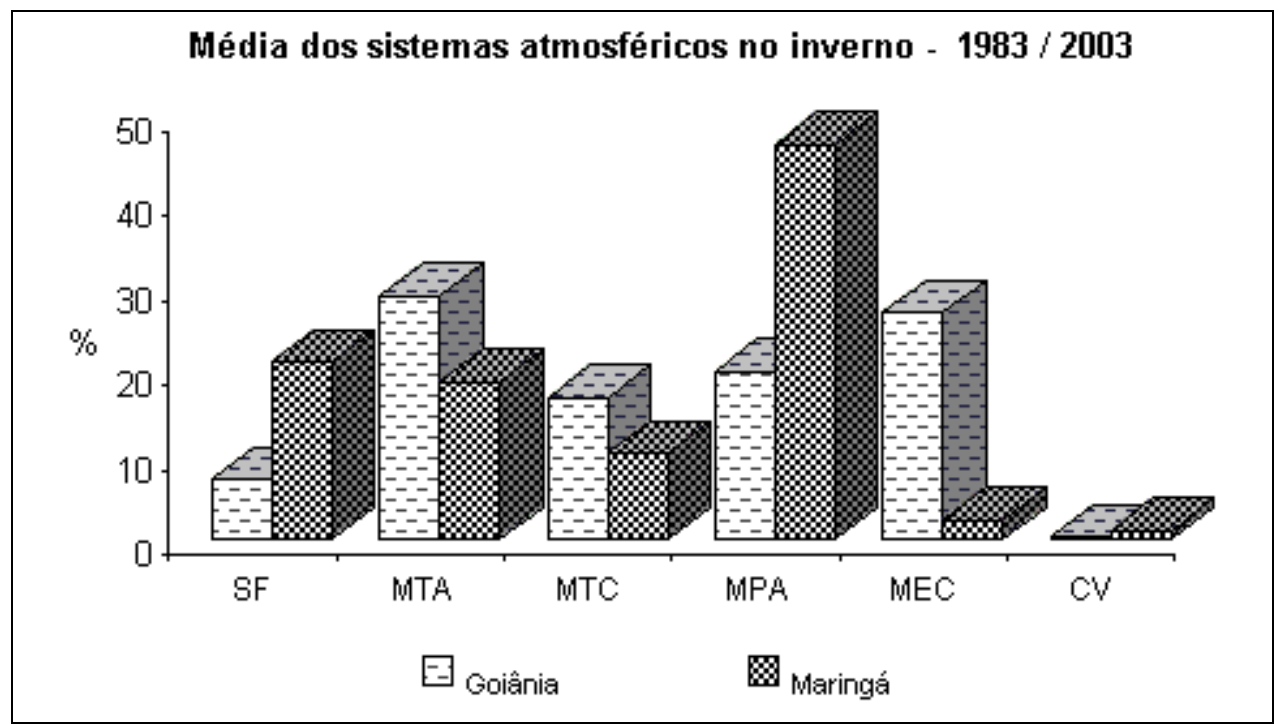

Figura 17. Porcentagem média da permanência dos sistemas atmosféricos em Maringá e em Goiânia na estação de inverno, no período entre 1983 e 2003.

No inverno, na área de estudo, a pluviosidade está condicionada aos avanços dos sistemas frontais. As chuvas provocadas por este sistema têm duração e intensidade controladas pelas condições atmosféricas, principalmente a umidade relativa do ar e a intensidade do sistema. À medida que os sistemas frontais avançam, as $\mathrm{mPa}$ impõem suas características e assimilam as características das áreas invadidas. Por essa razão, ao chegarem a Goiás, não causam alterações significativas no tempo e raramente formam precipitações. Por outro lado, o aumento da permanência da $\mathrm{mPa}$ e a menor atuação do SF em Maringá faz com que a pluviosidade diminua na região.

A primavera é novamente a estação de mudanças nas condições do tempo no Brasil Central. Os meses de setembro e outubro marcam o início do período chuvoso na série analisada. Em todos os anos, houve registros de, pelo menos, um episódio chuvoso no mês de setembro e a partir de novembro, as chuvas tornam-se constantes e abundantes, principalmente, em Goiás e norte do Mato Grosso do Sul. No sul desse estado e no Paraná, os principais episódios chuvosos continuam relacionados aos avanços dos sistemas frontais.

Os sistemas de baixa se ampliam significativamente em Goiânia com o início de dias mais longos a partir de outubro. Em Maringá, não são verificadas grandes alterações no tempo e na atuação dos sistemas atmosféricos. Mesmo porque, em setembro, é bastante comum a $\mathrm{mPa}$ avançar pelo interior do continente e, na altura do Sudeste do Brasil, deslocar-se para o oceano e permanecer sobre a costa Sul e Sudeste do Brasil por vários dias. A Figura 18 mostra a porcentagem de atuação dos sistemas atmosféricos em Maringá e em Goiânia na estação da primavera.

Nos meses mais quentes as chuvas convectivas são abundantes em Goiás e diminuem gradativamente na medida em que aumenta a latitude. Por outro lado, as chuvas frontais diminuem à medida que diminui a latitude.

Nos meses mais frios, as chuvas se limitam aos avanços dos sistemas frontais. Como os mesmos perdem suas características ou se desviam para o mar, as chuvas em Goiás ocorrem em episódios esporádicos. Em Maringá e no 
Mato Grosso do Sul, há anos em que o acumulado das chuvas frontais no inverno é comparável ao do verão.

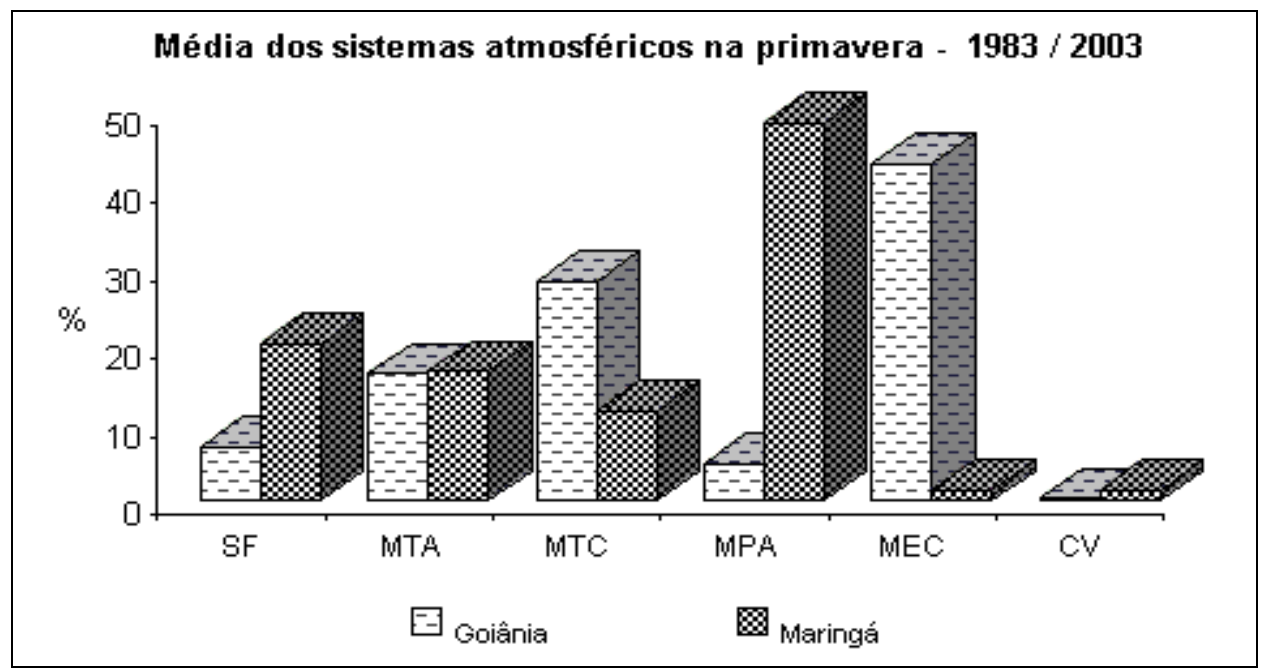

Figura 18 - Porcentagem média da permanência dos sistemas atmosféricos em Maringá e em Goiânia na estação da primavera, no período entre 1983 e 2003.

\section{A síntese da dinâmica das massas de ar}

O El Niño de 1980 foi de baixa intensidade e, por isso os elementos do tempo, temperatura, pressão, ventos e principalmente a pluviosidade apresentaram-se próximos as normais climatológicas do INMET (2006 on line) e também das médias da série. As análises revelaram que no verão, as massas de ar de origem polar (massa Polar atlântica - $\mathrm{mPa}$ ) avançaram pelo sul do Brasil e a sua trajetória e intensidade foram bastante variáveis. A grande maioria delas se deslocou para o Atlântico antes de atingir o Sudeste do Brasil. Por outro lado, durante 0 inverno se intensificaram. Um grande número de sistemas anticiclonais avançou pelo interior do Brasil e, somente depois de impor suas características sobre o Sul, Sudeste e parte do Centro-Oeste, deslocaram-se para o Atlântico.

Ao avançar pelo território brasileiro, o contraste térmico entre a mPa e as massas de ar que se encontram sobre a sua trajetória formam as frentes, responsáveis pelas chuvas frontais no Paraná do Mato Grosso do Sul e em Goiás, onde as chuvas frontais acumularam menos de $10 \mathrm{~mm}$ nos meses e maio a agosto.

Verificou-se que nos meses de abril e maio, os primeiros sistemas de alta pressão avançaram pelo interior do Centro-Sul do Brasil, causando chuvas frontais até no estado de Goiás. Essas massas de ar são de baixa umidade e após dominarem o tempo atmosférico na região, encerraram o período chuvoso para o estado de Goiás, principalmente.

Em toda a série estudada, o ritmo seguiu aproximadamente o verificado no ano 1980, embora houvesse variações significativas na intensidade, na freqüência e na evolução dos sistemas atmosféricos.

As séries de Maringá, Campo Grande e de Goiânia mostram um aumento da permanência da $\mathrm{mPa}$ e da $\mathrm{mEc}$, o que indica uma tendência de ampliação do limite norte de atuação das massas polares e também uma ampliação para sul 
do limite de atuação das massas equatoriais. A situação apresentada pelas três cidades demonstra que o limite de atuação da mPa estabelecido por ZAVATINI (1991) deslocou-se para o norte, conforme verificado pela análise dos dados de 1980 (BORSATO, 2006).

\section{CONSIDERAÇÕES FINAIS}

O estudo sintético das massas de ar e dos tipos de tempo diário permitiu o acompanhamento e a evolução dos sistemas frontais, ciclonais e anticiclonais, da gênese à dissipação. Os sistemas, massa Equatorial continental e Alta Subtropical do Atlântico ou massa Tropical atlântica são semifixos, considerando a área de origem e atuação. Por isso, eles foram considerados como sistemas responsáveis pelos tipos de tempo durante o período de atuação ou de influência na área de estudo.

A análise mostrou que o limite médio de atuação do Sistema Frontal e da massa Polar atlântica sofreu um deslocamento de pelo menos um grau para norte, em relação à posição estabelecida por ZAVATINI (1991), mas mostrou também que o limite meridional da atuação da massa Equatorial continental deslocou-se para sul.

O principal sistema atmosférico que teve o seu tempo de participação reduzido foi a $\mathrm{mTa}$ e isso revela o fortalecimento do aquecimento basal na região Centro-Oeste, que passa a sofrer maior influência da $\mathrm{mTc}$, $\mathrm{mEc}$ e $\mathrm{mPa}$. Além disso, o aquecimento basal pode ser o responsável pelo maior dinamismo dos sistemas, revelado pela tendência de diminuição da permanência dos sistemas frontais.

As chuvas apresentam uma variabilidade temporal, espacial e no volume, muito grande. Por isso, esta análise se limitou a estudar a sua gênese e foi constatado que as chuvas frontais mais intensas ou mais escassas estão relacionadas às intensidades e trajetórias dos sistemas frontais. Verificou-se também que a partir da década de 1990 a participação das chuvas convectivas está aumentando e é justificado pelo aumento da participação dos sistemas de baixas pressões no interior do Brasil, corroborando com as teorias do aquecimento global.

\section{REFERÊNCIAS}

BORSATO, V. A., 0 ritmo climático e episódios pluviométricos na bacia do rio Paraná no ano de 1980. Tese (parcial), (Doutorado) Nupélia, Universidade Estadual de Maringá. Maringá, 2006.

BORSATO, V. A. BORSATO F. H e SOUSA E. E., Análise Rítmica e a Variabilidade Têmporo - Espacial. In: VI Simpósio Brasileiro de Climatologia Geográfica. Teoria e Metodologia em Climatologia. Universidade Federal de Sergipe, Núcleo de pós Graduação Geográfica, Aracajú SE. Outubro 2004. Eixo 3 tema 3 - CD-ROM.

BRASIL. Ministério da Marinha. Serviço Meteorológico da Marinha. Cartas sinóticas. Rio de Janeiro, 1980/2003. CD-ROM. 
CPTEC/INPE. - CLIMANALISE: Boletim de Monitoramento e Análise Climática, Cachoeira Paulista, Disponível em: http://www.cptec.inpe.br/products/climanalise/ 1199/index.html. v 14 n 01 a 12. Acessado 25/03/2005.

COMUNELLO, E., 2001. Dinâmica de Inundação de Áreas Sazonalmente Alagáveis na Planície Aluvial do Alto Rio Paraná. Dissertação de Mestrado. UEM/CBS/PEA, Maringá-PR. 2001. 47 p. inédito.

DESTEFANI, E. V. Regime hidrológico do rio Ivaí-Pr. 2005. 93f. Dissertação (Mestrado em Geografia) - Departamento de Geografia, Universidade Estadual de Maringá. Maringá, 2005. p. 93.

DIAS, J Atlas Geográfico Digital do Mato Grosso do Sul. http://www2.uniderp.br/Atlas/ , consultado em 07 de Dezembro de 2006.

FERREIRA, C. C. 1989: Ciclogêneses e ciclones extratropicais na Região Sul-Sudeste do Brasil e suas influências no tempo, INPE-4812-TDL/359.

INSTITUTO BRASILEIRO DE GEOGRAFIA E ESTATÍSTICA. Diagnóstico Brasil: A ocupação do território e o meio ambiente. Rio de Janeiro: IBGE 1990.

ISTITUTO NACIONAL DE METEOROLOGIA (INMET). Dados climáticos diários (1980 - 2003), Brasília, DF, 2004. 1 CD ROM.

ISTITUTO NACIONAL DE METEOROLOGIA (INMET). Normais Climatológicas 1931/1990, On line 2006 http://www.inmet.gov.br/html/clima.php, consultado em 25/10/2006.

MONTEIRO, C. A. de F. Análise rítmica em Climatologia: problemas da atualidade climática em São Paulo e achegas para um programa de trabalho. Climatologia, São Paulo, n. 1, 1971 p. 1-21,

PÉDELABORDE, P. Introducion a l'étude scientifique du climat. SEDES, Paris, 1970. Neide Aparecida Zamuner Barrios, IPEA/UNESP. p. 246.

SANT'ANNA NETO, J. L., Clima e Organização do Espaço. Boletim de Geografia, Maringá, 16(1): Janeiro 1998. p. 118 - 131

SANT'ANNA NETO, J. L., e ZAVATINI, J. A. (Org.) 2000. Variabilidade e Mudanças Climáticas. Implicações ambientais e socioeconômicas, Maringá: Eduem 2000. p 95-119.

VAREJÃO-SILVA M. A., Meteorologia e Climatologia. Instituto Nacional de Meteorologia Brasília, DF, 2000 p 515.

VIANELLO, R. L., Meteorologia básica e Aplicações. Universidade Federal de Viçosa. Editora UFV 2000. p 450.

ZAVATINI, J.A. O Clima do Mato Grosso do sul - A dinâmica atmosférica e as chuvas subsidiando uma "proposta" de classificação climática de base genética. 
Anais do IV simpósio de Geografia Física Aplicada. V.1 - Sessões Técnicas. UFRGS, Porto Alegre, 1991. p. 528-534.

ZAVATINI, J.A., Desenvolvimento e perspectivas da climatologia geográfica no Brasil: o enfoque dinâmico, a noção de ritmo climático e as mudanças climáticas. In: SANT'ANNA NETO, João Lima, ZAVATINI, João Afonso (orgs.). Variabilidade e mudanças climáticas: implicações ambientais e socioeconômicas. Maringá: EDUEM, 2000. p. 225 - 251

ZAVATINI, J. A. A produção brasileira em climatologia: o tempo e o espaço nos estudos do ritmo climático. Terra Livre São Paulo, AGB Ano 19 - vol. I - n. 20 jan/jul. 2003 p. 65-100. 